\title{
Exchange Rate Uncertainty and Firm Profitability
}

\author{
Christopher F. Baum ${ }^{1}$ \\ Department of Economics \\ Boston College \\ Chestnut Hill, MA 02467 USA \\ Mustafa Caglayan \\ Department of Economics and Finance \\ University of Durham \\ Durham DH1 3HY, UK \\ John T. Barkoulas \\ Department of Economics \& Finance \\ Louisiana Tech University \\ Ruston, LA 71272 USA
}

1 Corresponding author: tel. 617-552-3673, fax 617-552-2308, email baum@bc.edu. 


\section{Exchange Rate Uncertainty and Firm Profitability \\ Abstract}

This paper investigates the effects of permanent and transitory components of the exchange rate on firms' profitability under imperfect information. Utilizing a signal extraction framework, we show that the variances of these components of the exchange rate process will have indeterminate effects on the firm's growth rate of profits, but will have predictable effects on its volatility. An increase in the variance of the permanent (transitory) component in the exchange rate process leads to greater (lesser) variability in the growth rate of the firm's profits, thus establishing that the source of exchange rate volatility matters in analyzing its effects. Implications of our theoretical findings for the empirical modeling of the underlying relationships are discussed.

\section{Introduction}

Since the breakdown of the Bretton Woods system of fixed exchange rates, both real and nominal exchange rates have fluctuated widely. This volatility has been cited by the proponents of managed or fixed exchange rates as detrimental, since exchange rate uncertainty would adversely affect the valuation of multinational firms. Models developed by Shapiro (1974) and Dumas (1978) predict that changes in exchange rates negatively impact a multinational firm's cash flows, its profitability, and therefore its market value. However, there has been limited empirical support for this hypothesis. Bartov and Bodnar (1994) find a significant (negative) correlation between abnormal returns of U.S. multinational firms and lagged changes in the value of the dollar. On the contrary, studies by Jorion (1990), Amihud (1993), and Bailey and Cheung (1995) fail to establish a significant relationship between contemporaneous dollar fluctuations and U.S. multinational firms' stock returns. A more fruitful avenue of research focuses on the relation of the second moments, namely, the relationship between exchange rate volatility and the volatility of firms' profit growth. ${ }^{2}$ Along these lines Bartov, Bodnar, and Kaul (1996) empirically examine the relationship between the second moment of exchange rate changes

2 The terms uncertainty, volatility, and variability are used interchangeably in this paper. 
and stock returns' volatility by comparing five-year periods before and after the breakdown of the Bretton Woods system. They find support for the hypothesis that increased exchange rate variability leads to increased volatility of multinational firms' stock returns.

The discrepancy between empirical results and general predictions of the previous models calls for a fresh look at the relation between exchange rate uncertainty and firm behavior. Unlike previous research which concentrates on the effects of gross exchange rate uncertainty, this paper attempts to deepen our understanding of the distinct effects of permanent and transitory components of exchange rate uncertainty on firm profitability. In our theoretical framework, based on signal extraction, we assume that the manager of a firm engaged in international trade distinguishes between those exchange rate changes which reflect permanent shifts, to which she must respond in her capital investment decisions, and those that capture short-lived transitory dynamics. Within this framework, we contribute to the literature in two directions. First, our theoretical results help explain the ambiguous empirical evidence regarding the relationship between exchange rate uncertainty and stock returns. We demonstrate that although the firm's profitability is sensitive to changes in the variances of the permanent and transitory components of the exchange rate process, the signs of those dependencies cannot be determined. Second, we rigorously examine the relationship between exchange rate uncertainty and the volatility of a firm's growth rate of profits, which is, to our knowledge, the first study to analytically derive these second-moment effects. We show that the variance of the firm's growth rate of profits is positively (negatively) related to the volatility of the permanent (transitory) component of the exchange rate process.

Since the specific source of exchange rate uncertainty matters in analyzing its effects on the behavior of the firm's growth rate of profits, evaluating exchange rate uncertainty without regard to its source fails to provide insights into managerial behavior. Any empirical testing of the underlying relationships between exchange rate volatility and the behavior of firm profitability that fails to explicitly model the permanent and transitory 
sources of that volatility is likely to result in misleading inferences.

The rest of the paper is constructed as follows. In Section 2, a signal extraction model is developed to investigate the effects of exchange rate uncertainty on the level and volatility of the firm's growth rate of profits. The analytical results are derived and presented in Section 3. We conclude in Section 4 with a summary of our theoretical findings and a discussion of their implications for empirical work.

\section{The Model}

In this section, we present the stochastic process assumed to govern the behavior of the nominal exchange rate, and then develop a simple signal extraction framework to analyze the effects of exchange rate uncertainty on the behavior of the growth rate of profits of a firm engaged in international trade.

\subsection{Modelling Exchange Rate Behavior}

We model the logarithm of the nominal spot exchange rate (measured as the domestic price per unit of foreign currency) as the sum of a permanent component and a transitory component. The permanent component is modeled as a random walk process and the transitory component as a stationary process, respectively, as

$$
\log x_{t}=\log e_{t}+u_{t}
$$

and

$$
\log e_{t}=\log e_{t-1}+\epsilon_{t}
$$

where $\log x_{t}$ is the logarithm of the observed nominal spot exchange rate and $\log e_{t}$ is the logarithm of the unobserved permanent component of the exchange rate, assumed to possess a stochastic trend and exhibit the driftless random-walk behavior in (2). The 
transitory component of the exchange rate process and the shock term to the permanent component are assumed to be mutually uncorrelated and respectively distributed as $N\left(0, \tau_{t}^{2}\right)$ and $N\left(0, \sigma_{t}^{2}\right) .{ }^{3}$ The normality assumption captures the idea that the probability of observing small changes is high whereas large variations in the permanent component are less probable.

Modelling the nominal exchange rate as a mix of a random walk and stationary components yields a nonstationary process, and it is consistent with the empirical evidence (see Baillie and Bollerslev (1989) among others). The permanent component represents the set of fundamentals determining the long-run equilibrium value of the exchange rate such as the present value of expected future realizations of domestic and foreign money stocks, real incomes, inflation rates, and current account balances. Since the stochastic processes for these fundamentals are likely to be integrated of order one $(I(1))$, the permanent component of the exchange rate is plausibly modeled as a random walk process. The transitory component is comprised of the effects of portfolio shifts among international investors (following Evans and Lyons (1999)), central-bank intervention, ${ }^{4}$ microstructure phenomena such as bubbles and rumors (excess speculation and bandwagon effects), and the effects of technical trading by chartists or "noise traders." Thus, the temporary component of the exchange rate process captures those exchange rate movements that cannot be explained by revised expectations of the underlying economic fundamentals. Alternatively, it could be interpreted as the transient dynamics of deviations from the long-run equilibrium value (a disequilibrium component). Such an interpretation of the nominal exchange rate process draws from Mussa's (1982) sticky-price model, which is a stochastic generalization of the Dornbusch (1976) exchange-rate overshooting model. The permanent-transitory decomposition of the exchange rate process is also consistent with the chartist-and-fundamentalist approach suggested by Frankel and Froot (1988)

\footnotetext{
3 Although it is possible to introduce high-frequency components in modeling $u_{t}$, doing so would complicate the analysis without affecting any of the subsequent results.

4 The central bank's actions may have permanent effects on the exchange rate to the extent that they signal permanent changes in the conduct of monetary policy (Kaminsky and Lewis (1996)).
} 
and empirically tested by Vigfusson (1996).

Given this decomposition, we include the change in the (unobserved) permanent component of the exchange rate as the appropriate state variable in the manager's optimization problem, as opposed to the change in the (observed) nominal exchange rate. Since changes in the nominal rate may reflect either fundamental shifts or transitory fluctuations from fundamental value, the manager should alter the capital stock only if the change has been determined to reflect a fundamental shift. In the presence of installation costs and/or delivery lags, it would not be optimal to adjust the capital stock in response to a short-term, transitory and inherently unpredictable exchange rate movement. ${ }^{5}$ Reaction to transitory changes in the exchange rate should be confined to firms' activities in the financial markets. ${ }^{6}$ It is therefore changes in the fundamental value of the foreign currency (the permanent component of the exchange rate) that should be taken into account by the firm in making capital investment decisions.

\subsection{Modelling Managerial Behavior under Exchange Rate Uncertainty}

We now specify the firm's optimization problem. Consider a firm engaged in international trade whose manager maximizes the discounted present value of its expected stream of future profits conditional on information available at time zero. Assume that the firm's technology is Cobb-Douglas and denote the capital stock, investment, permanent component of the exchange rate, and output prices by $K_{t}, I_{t}, e_{t}$ and $P_{t}$, respectively. The

\footnotetext{
5 Taylor and Allen (1992) and Cheung and Chinn (1999) report that foreign exchange dealers rely on technical analysis to form short-term exchange rate predictions, which tend to be self-fulfilling.

6 Although firms engaged in international activities could hedge the adverse effects of transitory shocks, the effects of persistent shocks (for example, to tastes and/or technology) to the exchange rate cannot be hedged away simply by using short-term hedging strategies.
} 
maximand is ${ }^{7}$

$$
V_{t}=E_{t}\left\{\sum_{i=0}^{\infty} \beta^{i}\left[e_{t+i}^{\gamma} P_{t+i}^{\gamma} A_{t+i} K_{t+i}^{\psi}-P_{t+i}^{I} I_{t+i}\right]\right\}
$$

where $E_{t}$ is the expectations operator conditional on the information set at time $t, \beta$ is the discount factor, $A$ is positive and nonstochastic (see footnote 7 ), and $P^{I}$ is the price of new investment goods. The maximization problem in (3) is subject to the equation of motion for capital

$$
K_{t}=(1-\delta) K_{t-1}+I_{t-1}
$$

where $\delta$ is the rate of capital depreciation. Investment expenditures this period are assumed to incur a one-period time-to-build, and only become productive in the following period. This time-to-build formalization reflects the fact that firms cannot instantaneously adjust the capital stock in the presence of construction and delivery lags. Thus, the manager must be forward-looking, since today's investment decision determines next period's capital stock. ${ }^{8}$

Substituting (4) into (3) and normalizing the output price to unity, the optimal capital stock for the next period can be derived by solving the following first order condition:

$$
\frac{\partial V_{t}}{\partial K_{t+1}}=\beta E_{t}\left[\psi e_{t+1}^{\gamma} A_{t+1} K_{t+1}^{\psi-1}+P_{t+1}^{I}(1-\delta)\right]-P_{t}^{I}=0
$$

This expression may be rewritten as

$$
E_{t}\left[\psi e_{t+1}^{\gamma} A_{t+1} K_{t+1}^{\psi-1}\right]=\beta^{-1} P_{t}^{I}-E_{t} P_{t+1}^{I}(1-\delta)
$$

where the right side of the expression may be defined as $c_{t}$, Jorgenson's user cost of capital,

7 The profit function in equation (3) is obtained by maximizing out the labor input. Maximizing the profit function $\pi_{t}=e_{t} P_{t} T K_{t}^{\alpha} L^{\zeta}-w_{t} L_{t}$ (where $T$ and $w$ denote the nonstochastic coefficient for technical progress and the wage rate, respectively) with respect to $L$ and substituting back into the profit function yields $\pi_{t}=e_{t}^{\gamma} P_{t}^{\gamma} A_{t} K_{t}^{\psi}$, where $\gamma=\frac{1}{1-\zeta}, \psi=\frac{\alpha}{1-\zeta}$ and $A_{t}=\left(\zeta T / w_{t}\right)^{\zeta \gamma}-w_{t}\left(\zeta / w_{t}\right)^{\gamma}>0$

8 The time-to-build approach was proposed by Kydland and Prescott (1982). It stands as an alternative to the quadratic adjustment cost approach employed in most Tobin's $q$ models of investment, and may be considered as a limiting case of the adjustment cost model: one in which instantaneous adjustments become infinitely costly. 
which we treat as nonstochastic. ${ }^{9}$ Having assumed that the permanent component of the exchange rate follows a log-normal distribution, $e_{t}^{\gamma}$ will also be log-normally distributed. Taking the logarithm of both sides of equation (6), we obtain

$$
(1-\psi) \log K_{t+1}=\log E_{t} e_{t+1}^{\gamma}+m_{t+1},
$$

where $m_{t+1}=-\log c_{t}+\log \psi+\log A_{t+1}$. Using the properties of log normality, we obtain

$$
(1-\psi) \log K_{t+1}=\gamma E_{t} \log e_{t+1}+\frac{\gamma^{2}}{2} \operatorname{Var}_{t+1 \mid t}\left(\log e_{t+1}\right)+m_{t+1}
$$

If the firm's manager could observe $\epsilon_{t}$, then she could perfectly predict the permanent component of the exchange rate which would prevail in the next period, and choose the level of investment which would provide the optimal capital stock next period. However, the manager does not observe $\epsilon_{t}$, but instead observes the (realized) nominal spot exchange rate given in equation (1), which is a mixture of permanent and transitory components. The innovation of the nominal exchange rate is by definition a noisy signal of the shock to the permanent component $\epsilon_{t}$, given by

$$
S_{t}=\log x_{t}-\log x_{t-1}=\epsilon_{t}+\Delta u_{t}
$$

Note that $\Delta u_{t}$ is the change in the transient component of the nominal exchange rate process, which hinders a perfect forecast of the change in the permanent component. Using the signal and the past realizations of the permanent component, ${ }^{10}$ it is possible to forecast the change in the permanent component of the exchange rate. It must be emphasized that unless the manager had some information on $\epsilon_{t}$, it would not be possible to improve upon the naive random-walk forecast of no change in the permanent com-

\footnotetext{
9 It is possible to model the problem by assuming that some or all investment goods are imported. This would complicate the analysis by introducing cost uncertainty in addition to revenue uncertainty. Our results hold in this case as long as cost uncertainty has a minor effect on profits (relative to revenue uncertainty), which will be the case if goods are more mobile than the factors of production.

10 Although the permanent component is not observable, its past values may be extracted from the history of nominal exchange rates as the solution to an optimal projection problem.
} 
ponent. However, conditioning on the signal, the manager can improve upon the naïve prediction of a zero value for $\epsilon_{t}$. The expected innovation in the permanent component of the one-period-ahead exchange rate at time $t$, given the signal $S_{t}$, and all other relevant information, is $E_{t}\left(\log e_{t} \mid S_{t}\right)-\log e_{t-1}=E\left(\epsilon_{t} \mid S_{t}\right)$. By making use of the standard formula for signal extraction, one can show that $E\left(\epsilon_{t} \mid S_{t}\right)=\lambda_{t} S_{t}$, where the signal-to-noise ratio is $\lambda_{t}=\frac{\sigma_{t}^{2}}{\sigma_{t}^{2}+\tau_{t}^{2}+\tau_{t-1}^{2}} .{ }^{11}$ We may now simplify equation (8) as

$$
\log K_{t+1}=\frac{\gamma}{1-\psi}\left[\log e_{t-1}+\lambda_{t} S_{t}\right]+\frac{1}{1-\psi} n_{t}
$$

where $n_{t}=\frac{\gamma^{2}}{2}\left[\sigma_{t+1}^{2}+\left(1-\lambda_{t}\right) \sigma_{t}^{2}\right]+m_{t+1} \cdot{ }^{12}$

Equation (10) relates the log of the firm's one-period-ahead capital stock to the past realization of the permanent component of the exchange rate and the expected value of the shock to the permanent component, as captured by $\lambda_{t} S_{t}$. The relationship depends upon both the variance of the shock of the permanent component and the variance of the noise term through $\lambda_{t}$ and $n_{t}$. Recalling that the production technology is Cobb-Douglas and the price of output is normalized to unity, we can rewrite the log of profits and express the growth rate of the firm's profits, respectively, as

$$
\log \pi_{t+1}=\gamma\left(\log e_{t}+\epsilon_{t+1}\right)+\frac{\gamma \psi}{1-\psi}\left[\log e_{t-1}+\lambda_{t} S_{t}\right]+\frac{\psi}{1-\psi} n_{t}+\log A_{t+1}
$$

and

$$
\log \frac{\pi_{t+1}}{\pi_{t}}=\gamma \epsilon_{t+1}+\frac{\gamma \psi}{1-\psi}\left[\epsilon_{t-1}+\lambda_{t} S_{t}-\lambda_{t-1} S_{t-1}\right]+\frac{\psi}{1-\psi} \Delta n_{t}+\log \frac{A_{t+1}}{A_{t}}
$$

Notice that the growth rate of the firm's profits has four parts. The first part captures the direct effect of a change in the permanent component of the exchange rate on the revenue stream. The second part captures the effect of exchange rate uncertainty on managers' capital accumulation decisions. The third and fourth parts of the expression reflect, respectively, the effects of changes in costs and technological change.

11 Although the expected value of the signal is zero, its realization is not generally zero.

$12 \operatorname{Var}_{t+1 \mid t}\left(\log e_{t+1}\right)=E_{t}\left[\log e_{t+1}-E \log e_{t+1}\right]^{2}=\sigma_{t+1}^{2}+\sigma_{t}^{2}\left(1-\lambda_{t}\right)$. 


\section{Analytical Results}

We first derive the effects of exchange rate uncertainty on the first moment (level) of the firm's growth rate of profits and subsequently on its second moment (volatility).

\subsection{Exchange Rate Volatilities and the Firm's Profit Growth}

We examine the effects of changes in the variances of the permanent and transitory components of the exchange rate process on the growth rate of the firm's profits by differentiating equation (12) with respect to $\sigma^{2}$ and $\tau^{2}$, respectively, and obtain

$$
\frac{\partial \log \frac{\pi_{t+1}}{\pi_{t}}}{\partial \sigma_{t}^{2}}=\frac{\gamma \psi}{1-\psi}\left[\frac{\eta_{t}^{2}}{\left(\sigma_{t}^{2}+\eta_{t}^{2}\right)^{2}} S_{t}-\frac{\gamma}{2}\left(\frac{\sigma_{t}^{2}\left(\sigma_{t}^{2}+2 \eta_{t}^{2}\right)}{\left(\sigma_{t}^{2}+\eta_{t}^{2}\right)^{2}}\right)\right]
$$

and

$$
\frac{\partial \log \frac{\pi_{t+1}}{\pi_{t}}}{\partial \tau_{t}^{2}}=-\frac{\gamma \psi}{1-\psi}\left[\frac{\sigma_{t}^{2}}{\left(\sigma_{t}^{2}+\eta_{t}^{2}\right)^{2}} S_{t}-\frac{\gamma}{2}\left(\frac{\sigma_{t}^{4}}{\left(\sigma_{t}^{2}+\eta_{t}^{2}\right)^{2}}\right)\right],
$$

where $\eta_{t}^{2}=\tau_{t}^{2}+\tau_{t-1}^{2}$. Equations (13) and (14) show that both the variance of the permanent shock $\left(\sigma_{t}^{2}\right)$ and the variance of the noise in the signal $\left(\tau_{t}^{2}\right)$ have an impact on the firm's growth rate of profits. However, the direction of change of these dependencies cannot be determined as the sign of each expression depends upon the sign of the signal, which may take on any value. Ceteris paribus, a depreciation of the domestic currency raises the firm's profits, while an appreciation of the domestic currency lowers its profits. Therefore, without knowledge of the direction of change of the exchange rate, one cannot determine the effects of increasing the volatility of either the permanent or transitory components of the exchange rate process on the firm's profit growth rate. These results can be summarized in the following proposition. 
Proposition 1 The effect of the variances of the permanent and transitory components driving the exchange rate process on the firm's growth rate of profits is ambiguous.

This ambiguity provides a theoretical rationale for previous researchers' failure to obtain a consistent empirical relationship between exchange rate uncertainty and the value of the firm. ${ }^{13}$ This analysis demonstrates that any seemingly conclusive empirical evidence regarding this dependence should be put into question as it may not be robust over time.

\subsection{Exchange Rate Volatilities and Variability of Profit Growth}

We now proceed to analyze second moment effects: the effects of the variances of the permanent component and the noise in the signal of the exchange rate process on the variance of the growth rate of the firm's profits. These analytical results are new to the literature. The variance of the growth rate of the firm's profits is given by

$$
\operatorname{Var}\left[\log \frac{\pi_{t+1}}{\pi_{t}}\right]=\gamma^{2} \sigma_{t+1}^{2}+\left(\frac{\gamma \psi}{1-\psi}\right)^{2}\left[\left(1-\lambda_{t-1}\right) \sigma_{t-1}^{2}+\lambda_{t} \sigma_{t}^{2}+2 \lambda_{t} \lambda_{t-1} \tau_{t-1}^{2}\right]
$$

Differentiation of equation (15) with respect to $\sigma_{t}^{2}$ yields the effect of a change in the variance of the permanent component of the exchange rate on the variance of the firm's growth rate of profits, which is given by

$$
\frac{\partial \operatorname{Var}\left[\log \frac{\pi_{t+1}}{\pi_{t}}\right]}{\partial \sigma_{t}^{2}}=\left(\frac{\gamma \psi}{1-\psi}\right)^{2}\left[\lambda_{t}\left(2-\lambda_{t}\right)+\frac{2 \eta_{t}^{2} \lambda_{t-1} \tau_{t-1}^{2}}{\left(\sigma_{t}^{2}+\eta_{t}^{2}\right)^{2}}\right]>0
$$

This relationship is unambiguously positive and the economic intuition underlying this result is straightforward. As the variance of the permanent component increases, the manager will be better able to discern changes in the permanent component from the

13 Even though the effects of exchange rate uncertainty on the firm's growth rate of profits imply the effects of that uncertainty on the firm's stock returns, the total effect of exchange rate uncertainty on the value of the firm can only be measured by evaluating the full effects on current and future profits. 
"noise" of the transitory component. In this case one should expect more volatility of the growth of the firm's profits, since the manager will continuously update her investment decisions as better information about the market and economic conditions accumulates. This result is summarized in the following proposition.

Proposition 2 The variance of the growth rate of the firm's profits is directly related to the variance of the permanent component of the exchange rate process.

By differentiating equation (15) with respect to $\tau_{t}^{2}$, we can show the effect of the variance of the transitory component of the nominal exchange rate on the variance of the growth rate of the firm's profits to be

$$
\frac{\partial \operatorname{Var}\left[\log \frac{\pi_{t+1}}{\pi_{t}}\right]}{\partial \tau_{t}^{2}}=-\left(\frac{\gamma \psi}{1-\psi}\right)^{2}\left(\sigma_{t}^{2}+\frac{2 \sigma_{t-1}^{2} \tau_{t-1}^{2}}{\sigma_{t-1}^{2}+\eta_{t-1}^{2}}\right)\left(\frac{\sigma_{t}^{2}}{\left(\sigma_{t}^{2}+\eta_{t}^{2}\right)^{2}}\right)<0 .
$$

This derivative states that an increase in the "noisiness" of the signal is negatively correlated with the variance of the growth rate of the firm's profits. Facing a noisier signal, the manager operates in a more uncertain environment. Increased uncertainty leads to more conservative behavior, as the manager will be less willing to react and change her investment decisions when the forecasts of changes in the permanent component of the exchange rate process are less precise. In this case, due to more cautious managerial behavior, the volatility of the firm's profit growth rate falls. This result is stated in the following proposition.

Proposition 3 The variance of the growth rate of the firm's profits is negatively related to the variance of the transitory component of the exchange rate process.

Propositions 2 and 3 clearly establish that the source of exchange rate uncertainty matters in determining its effects on the variability of the firm's growth rate of profits. An increase in exchange rate uncertainty may have a positive or negative effect on the growth rate of the firm's profits, depending upon the specific source from which it emanates. 


\section{Conclusions}

In this paper, we have presented a theoretical framework for managerial decisionmaking under exchange rate uncertainty. We have shown how imperfect information on the permanence of observed changes in the exchange rate affects the relationship between exchange rate volatility and the behavior of firm profitability. Our behavioral model generates predictions about the relationship between exchange rate uncertainty and the volatility of the rate of growth of the firm's profits. We show that greater exchange rate volatility associated with the permanent component of the exchange rate leads to more vigorous actions and greater variability in the growth rate of the firm's profits, while greater uncertainty in the transitory component of the exchange rate process leads to more conservative behavior, and a lower volatility of the firm's growth rate of profits. ${ }^{14}$

Our theoretical findings have important empirical implications. Researchers should strive to evaluate the permanent and transitory components of exchange rate uncertainty and quantify their differential impacts on the volatility of firms' growth rate of profits, and those measures derived from profitability, such as the stock market valuation of the firm. Simply estimating the total effect of exchange rate uncertainty on stock returns' volatility is likely to lead to incorrect inferences regarding the underlying relationships.

Although the model generates clear predictions of the signs of several important relationships, the result of an indeterminate sign on the relationship between exchange rate uncertainty and firm profitability may be equally important. A considerable body of literature has linked more volatile exchange rates to firms' behavior, performance, and valuation, with contradictory findings arising from empirical tests of these hypotheses. Our analytical results provide an answer to those contradictions, in that several interesting relations cannot be unambiguously signed. A decomposition of the exchange rate into permanent and transitory components sheds considerable light on these issues, but

\footnotetext{
14 Although the derivation focuses on the effects of exchange rate uncertainty, the model can be readily modified to incorporate the effects of any stochastic shocks to technology or prices on the level and volatility of firm profitability. However, these issues are beyond the scope of this paper.
} 
even with that decomposition, a number of important effects remain indeterminate. Our findings suggest that a number of the contradictions may be based on the countervailing effects that arise from a careful analytical treatment of these issues. 


\section{References}

[1] Amihud, Y. (1993), Evidence on Exchange Rates and Valuation of Equity Shares, in Y. Amihud and R. Levich, eds., Exchange Rates and Corporate Finance, Business One Irwin: Homewood, IL.

[2] Bailey, W. and Y. P. Cheung (1995), Exchange Rate Fluctuations, Political Risk, and Stock Returns: Some Evidence from an Emerging Market, Journal of Financial and Quantitative Analysis, 30, 541-561.

[3] Baillie, R. T. and T. Bollerslev (1989), Common Stochastic Trends in a System of Exchange Rates, Journal of Finance, 44, 167-181.

[4] Bartov, E. and G. M. Bodnar (1994), Firm Valuation, Earnings Expectations and the Exchange Rate Exposure Effect, Journal of Finance, 49, 1755-86.

[5] Bartov, E., Bodnar, G. M. and A. Kaul (1996), Exchange Rate Variability and the Riskiness of US Multinational Firms: Evidence from the Breakdown of the Bretton Woods System, Journal of Financial Economics, 42, 105-32.

[6] Cheung, Y. and M. Chinn (1999), Macroeconomic Implications of the Beliefs and Behavior of Foreign Exchange Traders, Working paper, Department of Economics, University of California at Santa Cruz.

[7] Dornbusch, R. (1976), Expectations and Exchange Rate Dynamics, Journal of Political Economy, 84, 1161-1176.

[8] Dumas, B. (1978), The Theory of the Trading Firm Revisited, Journal of Finance, 33, 1019-1029.

[9] Evans, M. and R. Lyons (1999), Order flow and exchange rate dynamics, Working paper, Haas School of Business, University of California at Berkeley.

[10] Frankel, J. and K. Froot (1988), Chartists, Fundamentalists, and the Demand for Dollars, Greek Economic Review, 10:1, 49-102.

[11] Jorion, P. (1990), The Exchange Rate Exposure of US Multinational Firms, Journal of Business, 63, 331-45.

[12] Kaminsky, G. L. and L. K. Lewis (1996), Does Foreign Exchange Rate Intervention Signal Future Monetary Policy? Journal of Monetary Economics, 37, 285-312.

[13] Kydland, F. and E. Prescott (1982), Time to Build and Aggregate Fluctuations, Econometrica, 50, 1345-1371.

[14] Mussa, M. L. (1982), A Model of Exchange Rate Dynamics, Journal of Political Economy, 90, 74-104.

[15] Shapiro, A. (1974), Exchange Rate Changes, Inflation and the Value of the Multinational Corporation, Journal of Finance, 30, 485-502.

[16] Taylor, M. P. and H. Allen (1992), The Use of Technical Analysis in the Foreign 
Exchange Market, Journal of International Money and Finance, 11, 304-314.

[17] Vigfusson, R. (1996), Switching between Chartists and Fundamentalists: A Markov Regime-Switching Approach, Working paper 96-1, Bank of Canada. 